\title{
Sequencing Run
}

National Cancer Institute

\section{Source}

National Cancer Institute. Sequencing Run. NCI Thesaurus. Code C148088.

The valid and completed operation of a high-throughput sequencing instrument for a single sequencing process. 